\title{
Radigales, J. (2017). El Espectáculo Operístico: Fundamentos e Historia. Barcelona: Huygens Editorial, 356 pp.
}

ISBN: 978-84-15663-73-7

La complejidad del género operístico, motivada no sólo por la heterogeneidad de estilos y escuelas que lo han enriquecido y transformado a lo largo de su historia, sino por sus rasgos intrínsecos determinados por la interdisciplinariedad artística (en las producciones elaboradas desde mediados del pasado siglo se podría hablar de intermedialidad, como bien apunta Radigales en su monografía), hace ardua la labor de síntesis a la hora de abarcarlo desde una perspectiva holística. A pesar de ello, el autor de El Espectáculo Operístico lo hace, concibiendo a tal fin un texto que organiza en dos partes bien diferenciadas: fundamentos directamente relacionados con el género e historia del mismo. Se trata de un gran acierto, por cuanto dichos fundamentos facilitan la comprensión de este complejo medio de expresión artística y preparan al lector lo que devendrá a continuación, que es una perfecta síntesis de la evolución de los principales testimonios operísticos estudiados en su contexto histórico-cultural, político y económico.

De gran interés es la parte dedicada a los fundamentos operísticos, la cual se nos antoja, no obstante, sintética en exceso. En algunos momentos, ello deviene en la escasa reflexión realizada sobre algunos aspectos que se consideran clave. Desde sus inicios y durante más de 400 años de historia, las distintas personalidades ligadas a este espectáculo han reflexionado (conscientemente o no; dando testimonio escrito o no) sobre el vínculo que debía existir entre texto y música. Dejando de lado las transformaciones estilísticas y estéticas operadas en cada época y cultura, la fuerza de atracción ejercida por uno de ellos (o por ambos) es la que ha determinado los grandes cambios en la historia del género, desde las primeras opere per musica hasta la Gesamtkunstwerk wagneriana, pasando por la escuela del bel canto italiano. Sobre estas cuestiones (así como, en general, todos los elementos constitutivos de la ópera) reflexionaron Bianconi (1986) y Dahlhaus (2005), quienes acuñaron el término de dramaturgia musical como la rama que teoriza precisamente sobre el drama con música. La convergencia de texto y canto (o, más bien, música en general), lleva consigo el cuestionamiento de lo verosímil del género -una preocupación ya patente desde los orígenes del mismo-, cuestión sobre la que reflexiona Radigales en los tres primeros capítulos (fundamentos musicales, literarios y teatrales, 


\section{RESEÑAS DE LIBROS}

respectivamente) pero también a lo largo de su exposición sobre la historia de la ópera. Sobre esta cuestión incidió especialmente Bianconi (1986), de manera que realizó una revisión histórica (indicando adeptos y detractores de lo aparentemente inverosímil de la ópera), reflexionó sobre algunas de las soluciones aportadas por compositores y literatos (que concibieron a veces situaciones y temas que creían propensos para justificar el drama a través del canto), y clarificó la razón de ser del canto, que es la de potenciar la expresión.

Pero la asunción de los fundamentos puramente musicales por parte del drama implica no sólo la estética del canto en lugar del declamado, sino todo lo que ello conlleva, especialmente, atendiendo a Dahlhaus (1986), en términos de «tiempo de la representación» -el cual queda determinado por la forma musical; por la duración de la ejecución- frente al «tiempo representado» -el sustrato "real" de la acción que se narra; el contenido dramático-. Lejos de restar valor al género operístico, esta divergencia lo dota de una gran capacidad para expresar afectos, sentimientos y situaciones dramáticas; asimismo, permite la simultaneidad de los mismos, posible gracias a los concertantes. Atendiendo a las cualidades temporales propias del teatro de ópera, muchas de las obras de este género (especialmente en los siglos XVIII y XIX) han estado supeditadas a una organización interna basada en la alternancia de momentos de carácter estático (generalizando, el aria) frente a otros más dinámicos por cuanto a tiempo dramático (o de la representación) se refiere (recitativo). Se trata de un aspecto que es tenido en cuenta por Radigales en el Capítulo 3, dedicado a los fundamentos teatrales. Sin embargo, cuando habla de la estructura interna de la ópera, la forma en que está organizado el discurso puede dar lugar a equívocos o confundir al lector. Esto se debe a que no se clarifica ciertamente lo que es un aria (especialmente, la que adquiere su significado pleno desde el s. XVIII) musical y dramáticamente hablando; ello no se comprende hasta que, más tarde, se llega a la definición del recitativo, momento en el que el lector lo puede deducir. En estrecha relación con lo anterior, tampoco queda bien claro el esquema de lo que Powers (1987) denominó solita forma, una convención estructural fundamental para la comprensión de la ópera decimonónica ${ }^{1}$. Así, por ejemplo, pone al mismo nivel de organización interna la cabaletta -sección conclusiva de un aria o dúo, de carácter brillante, extrovertida y fogosacon la cavatina, que en el Barroco designaba un aria corta pero que en el Romanticismo quedó plenamente identificada con el aria de salida de un personaje (y, por tanto, no tiene connotaciones de tipo estructural).

En este sentido, las tipologías estructurales que incluye Radigales (bien esquematizadas en la p. 43) obedecen a los rasgos del repertorio dieciochesco, lo cual plantea problemas a la hora de abarcar la ópera Romántica (de la que no se cita, por ejemplo, la tipología del aria di parzia -sí que se contempla en los apartados pertinentes dedicados a la historia del género-), por cuanto en esta época los dúos experimentan un tratamiento estructural similar a las arias (en la tabla se contemplan dentro de los

\footnotetext{
${ }^{1}$ A partir de las óperas de Rossini y hasta entrado el s. XIX, Powers (1987) analiza la estructura que podemos encontrar claramente y de forma diferenciada (y siempre con el riesgo de generalizar en exceso) entre los dúos (scena - tempo d'attacco - adagio o cantabile - tempo di mezzo - cabaletta), las arias (igual que el dúo, pero exentas de tempo d'attaco al no necesitar de momento dialógico, en el cual tiene lugar la aparición en escena del otro personaje, dando así lugar al dúo), y los números de conjunto (scena - tempo d'attacco - pezzo concertato - tempo di mezzo-stretta).
} 


\section{RESEÑAS DE LIBROS}

concertantes), y los recitativos se utilizan de forma más compleja dentro de la estructura de los números en los que se dividía cada acto (con ellos se construían las scene y tempi d'attacco y di mez:o -ver la nota al pie precedente-).

En la misma línea, desde el punto de vista estructural, una profundización en la relación práctica existente entre texto y música habría permitido conectar coherentemente con todo lo anterior el discurso ofrecido en el capítulo dedicado a los fundamentos literarios, por cuanto los libretistas (hablamos nuevamente de los siglos XVIII y XIX, en especial) concibieron el drama ajustándose en carácter y versificación a los requerimientos del recitativo y el aria o, en definitiva, de las secciones dinámicas y estáticas ${ }^{2}$. No obstante, no deja de resultar de interés dicho Capítulo 2, que ofrece datos interesantes, con ejemplos bien fundamentados, sobre el trabajo de los libretistas (que parte en muchas ocasiones de la adaptación de obras teatrales y novelas preexistentes) y la complicada labor de ensamblaje con los compositores. Lo mismo sucede con el resto de capítulos de esta primera parte de la monografía, que ofrecen un panorama sintético pero muy completo: tipologías vocales utilizadas en la ópera; aspectos dramatúrgicos relacionados especialmente con la puesta en escena ( $\mathrm{y}$ a tener en cuenta, por tanto y especialmente, por el director musical y el de escena); aspectos sociales, políticos y puramente arquitectónicos de los teatros de ópera; modelos de gestión y programación en Europa, Estados Unidos y Asia, así como el equipo artístico existente detrás de una producción; la crítica, con algunos apuntes sobre el papel del crítico y los aspectos que debería tener en cuenta ${ }^{3}$; medios de comunicación, que incluye una reflexión con una especial atención a los nuevos medios de difusión como son las salas de cine, las redes sociales e Internet en general; y la relación -muchas veces mutuaentre la ópera y el cine, un apartado muy bien expuesto y que deja entrever los profundos conocimientos del autor en la materia.

Con respecto a la parte histórica, que ocupa los últimos diez capítulos, presenta la evolución del género de una forma bien estructurada, sin una excesiva dependencia de la categorización por períodos (Barroco, Clasicismo, Romanticismo, etc.) ni por siglos, como podemos observar en algunas de las monografías todavía de referencia que tratan la historia de la ópera en su totalidad ${ }^{4}$. La desarrollada por Radigales presenta una estructuración similar, por ejemplo, a las de Alier (2002) y Kimbell (1991), si bien estas se centran exclusivamente en la historia de la ópera, y la última de ellas únicamente en el ámbito italiano; asimismo, cabe destacar que la que es objeto de reseña, aunque muy sintética, es la más completa, pues contempla prácticamente todos los estilos y tendencias, en especial la riqueza que aportaron las escuelas nacionales (una cuestión mucho más compleja que lo que se nos presenta en otros trabajos) y del s. XX. No obstante, quizá habría sido deseable

\footnotetext{
${ }^{2}$ Es interesante al respecto el estudio realizado por Osthoff (1986).

3 Al ya de por sí completo listado de "preguntas" que debería formularse la crítica, podrían también añadirse los aspectos relativos a la dirección artística y a por qué se han tomado: versión adoptada (en caso de existir varias), cortes operados, modificaciones de la partitura y/o del libreto, plantilla orquestal utilizada, etc.

${ }^{4}$ Es el caso, por ejemplo, de la realizada por Parker (1994), citada en algunos lugares por Radigales. También es el caso del libro de Snowman (2009), aunque centrado especialmente en los procesos histórico-sociales y económico-empresariales en torno a los cuales se gestó la ópera, haciendo un repaso por toda su historia; no obstante, sigue dependiendo mucho de categorizaciones temporales que no se adaptan a dichos cambios (1600-1800; 1800-1860; 1860-1900; 1900-1950).
} 


\section{RESEÑAS DE LIBROS}

estructurar la parte dedicada al s. XIX de otro modo. Así, convendría haber dado fin al capítulo dedicado a la "hegemonía italiana" con las obras de Verdi, destinando el movimiento de Scapigliatura a un lugar introductorio dentro del apartado dedicado al verismo. De esta forma se evitarían grandes saltos temporales y estilístico-estéticos, acentuados también cuando se trata la ópera alemana (con el gran coloso que fue Wagner) antes que la francesa. Ello habría permitido establecer una relación más próxima entre los productos de compositores italianos y la escena parisina a partir de la década de los $30 \mathrm{y}$ hasta mediados de siglo. A su vez, tratar la grand opéra antes que la ópera alemana habría facilitado preparar el terreno a las óperas románticas de Wagner (sobre ello nos detendremos más adelante). A pesar de ello, la complejidad de la escena operística decimonónica y las constantes influencias entre las distintas escuelas hace dificultosa la labor de estructuración, más aún si se quiere atender a criterios pedagógicos.

Por cuanto concibe el espectáculo de ópera tanto desde una perspectiva dramatúrgica y conceptual (y desde una óptica plenamente actual) como histórica, el trabajo de Radigales debería constituir una obra de referencia destinada tanto a estudiantes de conservatorio y universitarios como a lectores que sientan curiosidad por la ópera, como el propio autor indica en el apartado introductorio ${ }^{5}$. El fin último, por tanto, no es aportar nuevos datos o interpretaciones al campo de la historia de la ópera o de sus rasgos dramatúrgicos y de todo lo relacionado con el mercado operístico actual. A tal fin, ya existen trabajos como los de Bianconi y Pestelli (1987-88), que tratan todo el aspecto teórico y técnico, así como el sistema productivo y las características del teatro de ópera; Lindenberger (1998), que aporta una síntesis histórica y reflexiona sobre el estatus social del género, así como sobre la reinterpretación del pasado por parte de directores musicales y de escena para legitimar el presente; Abbate y Parker (2012), con especial énfasis en el mercado operístico desde una perspectiva histórica; Grout y Wigel Williams (2003), que examina no sólo el repertorio, sino la evolución del género, tratando áreas geográficas como Finlandia, América y China; de nuevo Bianconi y Pestelli (2002), centrados en todo lo relacionado con el proceso de producción del espectáculo operístico y con el producto en sí mismo y su evolución desde los inicios; Symonds y Karantonis (2013, en colaboración), sobre la recepción, producción, difusión y reinterpretación a través de los media, etc.; y Fryer (2014, también en colaboración), acerca de la ópera en la actual época de los media (incluye reflexiones sobre el nuevo público de ópera, la crítica, la industria de las grabaciones, los cantantes, la ópera y los medios audiovisuales y cine, y cuestiones de escenografía y dramaturgia). No deja de resultar llamativo el hecho de que ninguno de estos trabajos se cite ni utilice en la monografía de Radigales, así como tampoco, por ejemplo, el de Till (2012, en colaboración), que consideramos fundamental para la primera parte del estudio, ya que trata todo lo relativo a las instituciones (estado, sociedad, mercado operístico, teatros de ópera y audiencias), componentes (los media en la ópera, voces y cantantes, ópera y formas de producción teatral, tecnologías), formas (dramaturgia operística, género y poética, la

\footnotetext{
5 Teniendo en cuenta tal propósito, habría sido, no obstante, aclarar determinada terminología accesible en un principio a un lector con conocimientos musicológicos especializados. Es el caso, por ejemplo, de madrigalismo, arioso, stile rappresentativo, stile concitato, déclamation mélodique, bajo continuo, etc., todos ellos (excepto el último) concentrados en una sola página (p. 149).
} 


\section{RESEÑAS DE LIBROS}

obra -textos, representaciones, recepción, repertorio-), estudios de género, ópera e identidad nacional, etc.

Las fuentes utilizadas son, no obstante, suficientes para la elaboración de una monografía sobre los temas que trata, especialmente en lo que respecta a la historia de la ópera (utiliza casi un centenar de fuentes, algunas sobre la historia de la ópera en general, pero la gran mayoría centradas en la vida y obra de los compositores de ópera más representativos, mientras que otras están focalizadas en un periodo, escuela, tradición o estilo concreto, en la historia social o la estética) y a los medios de comunicación de masas y el cine puestos en relación con el hecho operístico, su gestión, programación y difusión. Ello contrasta, por otra parte, con la escasez de referencias utilizadas para el capítulo dedicado al teatro de ópera (prácticamente inexistentes) y para los destinados a los fundamentos musicales, literarios y teatrales (en comparación con lo descrito anteriormente). En este sentido, el lector podría haberse interesado por las fuentes de las que se toma la información, por ejemplo, de la forma en que está estructurada una ópera, del hecho de que "Rossini rechazó totalmente el uso de la voz plena y siguió reivindicando el falsete" (p. 25), de las soluciones orquestales y tonales para distintos tipos de escenas en las opere serie (p. 172), de las grandes exigencias demandadas por Verdi al reparto solista que protagonizó el estreno de su Macbeth (p. 241), de los análisis realizados a las óperas de Puccini, del apartado completo dedicado a la opera buffa y el Singspiel y del destinado al "antes y después de Wagner" (este último está poco documentado y constituye un listado de compositores y obras que se presentan inconexos, sin existir reflexión sobre lo que supusieron -o no- para el desarrollo de la ópera alemana). A pesar de todo, no se observan apenas descuidos a la hora de citar, pues prácticamente todo lo que es citado en el cuerpo textual aparece contemplado en el aparato bibliográfico, a excepción del trabajo de Moindrot $(1993)^{6}$, el de Porter $(1988)^{7}$, el de Carner (1988) ${ }^{8}$, el de Ashbrook y Budden $(1988)^{9}$ y el propio de Radigales (2005) ${ }^{10}$. Asimismo, se observan algunas erratas al respecto, como, por ejemplo, la fecha de edición del libro de Radigales y Villanueva (en algunos momentos -p. 134- aparece fechado en 2010, mientras que en la bibliografía se data en 2011). Por otro lado, cabría haber citado individualmente a los autores de las distintas voces extraídas del New Grove en lugar de citar únicamente al editor (Sadie, 1998), para poder así diferenciarlos convenientemente.

Por otro lado, a pesar de ofrecer, como ya hemos subrayado, una síntesis muy completa de la historia de la ópera, consideramos que adolece de algunas lagunas o de aspectos que no están plenamente desarrollados. Dado que se trata de una monografía destinada a estudiantes y un público "entusiasta o curioso" por la ópera, se considera que no quedan bien expuestas las diferencias estilístico-formales existentes entre lo que era la tragédie lyrique y la ópera italiana desde la segunda mitad del s. XVII; sí que se muestran

\footnotetext{
${ }^{6}$ Deducimos que se trata de Moindrot, I. (1993). L’opéra seria, ou le règne des castrats. Paris: Fayard.

${ }^{7}$ No hemos podido identificar la procedencia de este trabajo de Andrew Porter.

${ }^{8}$ Se refiere probablemente a Carner, M. (1988). Puccini: A critical Biography. New York: Holmes and Meier.

${ }^{9}$ En este caso sí que aparece, pero no es fácil de establecer la correlación, pues se citan parte de los autores, Ashbrook y Budden, omitiéndose el primero que aparece referenciado al final (Gosset).

${ }^{10}$ En ocasiones (por ejemplo, en la p. 328) no se especifica si alude a la publicación de 2005a o a la de 2005b.
} 


\section{RESEÑAS DE LIBROS}

claras las características de la primera, pero no se explica a qué se contrapone esa preeminencia del recitativo y lo dramático (se arroja algo de luz en la p. 170, si bien habría sido deseable profundizar más en esos rasgos definitorios, dada la importancia que cobrarán en un futuro a la hora de diferenciar las escuelas francesa e italiana). El siguiente lugar que merecería mucho más detenimiento es el apartado dedicado a la grand opéra francesa, cuyo influjo fue determinante para el devenir de las óperas compuestas hacia la mitad del s. XIX. Aunque el punto de partida sería La muette de Portici de Auber (1828), cabría haber subrayado la importancia crucial que desempeñó el Guillaume Tell de Rossini (no tanto respecto a la recepción del público, sino al influjo en la obra de los compositores posteriores que escribieron para la escena parisina), a quien Radigales describe casi únicamente como heredero -aunque renovador- de la tradición de la ópera cómica napolitana, de las innovaciones de Mozart y de la ópera seria. También habría sido conveniente profundizar más en la figura de Meyerbeer (a pesar de que su obra sea injustamente infravalorada en la actualidad), tanto en lo relativo a sus óperas en sí mismas (salvo la breve alusión a Les Huguenots) como en lo que respecta a sus soluciones líricodramáticas en torno al drama histórico ${ }^{11}$; tampoco se hace alusión a la buscada espectacularidad y monumentalidad realizada a todos los niveles, el gusto por el exotismo, etc. Estrechamente ligado a lo anterior está el hecho de que sólo se analiza la obra Wagneriana a partir de la tetralogía, de manera que apenas se habla de sus óperas románticas, ligadas en buena medida a la tradición de la grand opéra y que alcanzaron una importancia crucial para las innovaciones introducidas en las óperas que vieron la luz durante los años 1860 al 1880. De hecho, no deja de resultar curioso que el discurso utilizado para describir la producción wagneriana quede organizado cronológicamente a la inversa, es decir, de forma análoga al proceso de escritura (literaria) por parte de Wagner del Ring des Nibelungen, lo cual termina por no dejar lugar a una puesta en valor de obras como Rienzi (1842), Der Fliegende Holländer (1843), Tannbäuser (1845) y Lohengrin (1850). Asimismo, y a pesar de la gran cantidad de trabajo dedicado a su obra teórica e ideas del drama y la Gesamtkunstwerk, así como a sus ideales, pensamientos y su relación con los dramas escritos y cómo los enfoca, se echa de menos una síntesis de su estilo, de cómo estructura la partitura final a todos los niveles y de la ruptura que supuso respecto a la tradición anterior.

Por lo que respecta al tema de los nacionalismos y la ópera, es de elogiar el hecho de que el autor incluya un merecido apartado dedicado a la ópera en España, la eterna ausente de muchas historias de la ópera universales. No obstante, y a pesar de que los espacios dedicados a los nacionalismos de los considerados por mucho tiempo países de la periferia adolecen de una excesiva labor de síntesis, el destinado a la ópera española hace poca

\footnotetext{
11 Resumidamente, se podría caracterizar, entre otros aspectos, por: un nutrido elemento orquestal, de gran riqueza tímbrica, que cobra un gran protagonismo, así como de numerosos temas y motivos recurrentes, todo lo cual adquiere una clara función dramática; prolongados acordes de séptima sobre la sensible que imprimen una gran tensión (y, en general, armonías ricamente adornadas) y fórmulas asociadas al religioso; recurso a la tradición histórica musical anterior, algunas veces imaginada; diferenciación psicológico-musical aplicada en la verticalidad de un concertante; importancia dada a los grandes números de conjunto, que sobresalen muchas veces por encima de las arias y los dúos; coros puestos en boca del pueblo, que es tratado como un protagonista más de la trama; búsqueda de la diversidad y el contraste de las emociones; etc. Ver al respecto: Lacombe (2001), Everist (2005) y Döhring (1986).
} 


\section{RESEÑAS DE LIBROS}

justicia a la relativamente rica variedad de propuestas que se hicieron en España (independientemente de su mayor o menor protección y aceptación y, por consiguiente, su irremediable fracaso). En este sentido, el discurso se centra en exceso en los textos teóricos y reflexiones de Tomás Bretón (imprescindibles, no obstante, para comprender las razones del fracaso de la ópera en España), y se obvian por completo (o sólo se citan) personalidades decisivas en el panorama operístico nacional como Emilio Serrano, Ruperto Chapí o Felip Pedrell, que prepararon el camino a las generaciones futuras, las cuales sí tuvieron fortuna fuera de su país de origen (en el terreno operístico, Albéniz, Granados y Falla), no sólo a nivel teórico, sino también musical, pues comenzaron a dar los primeros frutos de lo que denominamos "nacionalismo de las esencias". Construido así el discurso, da la sensación de que antes de la Pepita Jiménez de Albéniz (1896) la ópera de autoría española no existió o, en su caso, era plenamente deudora de la italiana (italianismo que fue cierto en la mayoría de los casos hasta la década de 1860, inclusive). En definitiva, sería lamentable que el lector pudiera opinar, tras leer este apartado dedicado a la ópera en España, lo mismo que el reputado crítico Peña y Goñi $(1881)^{12}$, así como otros muchos del mismo parecer, como Fernán Flórez, quien escribió con motivo del estreno y estrepitoso fracaso en el Real de la ópera Elpríncipe de Viana, de Tomás Fernánde Grajal:

Para el poema épico y para un drama musical se necesita genio. Ese feliz equilibrio del saber técnico y de la inspiración grandiosa parece haber sido negado a los españoles, que no tenemos ni un verdadero poema ni una verdadera ópera (Fernán Flórez, 1885).

Por otra parte, aunque se trata de casos muy puntuales, cabría realizar algunos apuntes históricos que pueden corregir o dar otra perspectiva a hechos también muy concretos. Cuando habla de la querelle des Bouffons, acaecida en París entre 1752 y 1754 con motivo de la puesta en escena en la Académie royale de musique del intermezzo cómico La serva padrona de Pergolesi, menciona que, no obstante, la ópera de más éxito "fue en realidad Bertoldo in Corte" de Ciampi, representada en 1754; en este sentido, no es de extrañar que se tomase como icono la obra de Pergolesi, teniendo en cuenta que la de Ciampi se estrenó cuando ya prácticamente había finalizado dicho debate. Respecto al leitmotiv, se debe ser precavido a la hora de atribuir su uso a un compositor, como Radigales hace (p. 279) en este caso con la obra Roméo et Juliette (1867) de Gounod: aunque se trata, en efecto, de un compositor de grandes inquietudes y erudición compositiva, en sus óperas no hará sino un uso de sonoridades y temas reminiscentes (que, obviamente, no sólo cita, sino que transforma cuando la situación dramática lo requiere, si bien de forma ingeniosa), pero se trata de un recurso utilizado en muchas de las óperas compuestas en el tercio de siglo

12 Peña y Goñi introducía su libro titulado La ópera española y la música dramática en España en el siglo XIX afirmando tajantemente: "¿Existe la Ópera española? No; la Ópera española no existe; la Ópera española no ha existido nunca” (p. 14). Se trata, no obstante, de un libro escrito en 1881, cuando se habían estrenado poco más de una decena de óperas en España orientadas conscientemente al establecimiento de la ópera nacional, y que dedica muy poco espacio (a pesar de las casi 700 páginas que ocupa) a la propia cuestión de la ópera nacional, a lo que se une que en este poco espacio no tienen prácticamente cabida las obras estrenadas en la década de 1870 (las propiamente consideradas dentro de la corriente nacionalista). 


\section{RESEÑAS DE LIBROS}

anterior. Por otro lado, resulta curiosa (y, aunque pueda parecer anecdótica, es representativa de lo que constituyeron los ideales en torno a la grand opéra) la afirmación que se hace sobre el uso del saxofón. Inventado en 1844, este instrumento se empleó por primera vez en el mundo de la ópera, en la obra de G. Kastner titulada Le Dernier Roi (estrenada el mismo año de 1844). Posteriormente, Meyerbeer, entusiasta del instrumento desde su invención, lo utilizó en L'Africaine (1864) y después Saint-Saëns en Les Noces e Promethes (1867) y Ambroise Thomas en Hamlet (1868), pero Thomas no fue, como hemos podido comprobar, el primero en hacerlo, tal y como afirma Radigales (p. 274). No obstante, no sería sino Bizet quien lo popularizó en L'Arlesienne en 1873 (Asensio, 1998). Por lo que respecta a Verdi, debido a la complejidad de su relación con el movimiento del Risorgimento italiano, cabe abordar el tema (objeto de numerosos debates en el mundo de la musicología, si bien parece que en los últimos años los estudios parecen arrojar luz al respecto) con mucha cautela. Es cierto que Verdi se terminó convirtiendo en símbolo de la lucha por la independencia italiana (de ahí la expresión Viva VERDI -Vittorio Emanuele, Re d'Italia-, popularizada, no obstante, a finales de 1858, es decir, más de 16 años después del estreno de Nabucco, así como posterior a muchas de sus óperas "de corte risorgimentale", como I Lombardi, Ernani o Attila), pero es mucho más relativo su sentimiento de "responsabilidad hacia una Italia unida" (p. 236). Por supuesto, nadie pone en duda que ansiara la independencia y unificación italiana y que concibió momentos que el público convirtió en himnos de exaltación patriótica, pero su lucha quedó lejos de lo político, a pesar de que en 1861 fuese nombrado, en contra de sus deseos (instado por el Conde de Cavour), diputado del Parlamento italiano, institución en la que apenas participó y puesto del que renegó, alegando que "el Verdi diputado no existe"13.

En cuanto a la expresión, se trata de un libro denso (por la gran labor de síntesis efectuada) pero de fácil comprensión. En la cuestión del estilo, sólo nos llama la atención el uso casi sistemático en muchos lugares (en más de un centenar de ocasiones), a modo de leitmotiv, del punto y seguido en lugar de la coma o punto y coma, lo cual dificulta la lectura y obliga a volver a retomar el párrafo ${ }^{14}$. Por supuesto, como cualquier escrito científico, no está exento de erratas y de algunos errores ortográficos ${ }^{15}$, aunque se deben en este caso a

\footnotetext{
13 Ver al respecto el estudio realizado por Gossett, (2012). Ver también Parker (2012) y Pauls (1996).

14 Ver, a modo de ejemplo, las páginas 13, 14, 27, 94, 173, 184, 219, 234, 237, 256, 295, 309, 311, 315,336 y 345 , en las que se hace especialmente patente.

${ }^{15}$ P. 26(3), "primeras óperas"; p. 61, en el título del capítulo se repite la palabra "Fundamentos"; p. 62(4), “En el siguiente capítulo...”; p. 112(2), "ángulos de visión”; p. 152(1), "Signor, sempre mi vedi”; p. 170(5), “dejọ"; p. 174(2), idem que la anterior; p. 174(5), "encintas "; p. 182(2), "un sencillo”; p. 190(7), "óperas cómicas”"; p. 191(5), "commedia per musica"; p. 193(3), "consiguió"; p. 193 (nota 37), "Una cosa rara ossia Bellezza ed onestă" (y cursiva); p. 194 (nota 39), "Il matrimonio segreto" (cursiva); p. 198(2), "escrita en diecinueve años antes"; p. 202(3), "absolutamente"; p. 209(3), falta signo de apertura de comillas en la cita de Schmid (2009); p. 213(4), “difusión de la literatura europea”; p. 228(2), “así como su capacidad...”; p. 237(3), "Cortigiannil”; p. 240 (nota 66), "segunda escena del acto"; p. 247, "Sturm und Drang" (con cursiva); p. 250(1), "La conocida como Leonora-1"; p. 252(3), “Aen Leipzig [...] Harnoncourt”; p. 252(4), "que sirven para pintar"; p. 253(3), "Fracasó su estreno"; p. 253(6), "(que incluye veinte óperas)" (falta cerrar paréntesis); p. 256(4), "para el compositor era el núcleo"; p. 260(4), "habita en nuestro recuerdo"; p. 264(6), "una síntesis personal que Wagner diseñó"; p. 267(5), "según algunos teóricos"; p. 274(2), "Rachel, quand du Seigneur"; p. 275(1), "Berlioz (1803-1869)" (falta paréntesis de apertura); p. 276(5), "(estrenada póstumamente en 1890)"; p. 277(4), "Este se pone de manifiesto en"; p. 294(1), "uno de los compositores"; p. 299(4), "fundó y dirigió"; p. 300 (2), "la maravillosa válvula que sirve"; p. 303(1), “todọs ellos han sido algunos"; p. 306(1), "a pesar de
} 


\section{RESEÑAS DE LIBROS}

una falta de revisión rigurosa, a lo que se une que algunas erratas pueden confundir al lector, como es el caso, por ejemplo, de la fecha de fallecimiento de Rossini (1868, y no 1848, año en que murió Donizetti), o del número de años a lo largo de los que se representó Der Stein der Weisen oder Die Zauberinsel de Schikaneder (cuatro -y no 24- entre 1790 y 1794).

A pesar de las apreciaciones realizadas, El espectáculo operístico de Radigales es una obra de gran interés para cualquier estudiante o diletante interesado la ópera en general. En este trabajo, podrá dar respuesta a las inquietudes planteadas en torno a los rasgos diferenciadores del género, las características vocales y las tipologías utilizadas, y la evolución estilística y estética experimentada a lo largo de su historia, una historia en la que no se descuidan apreciaciones sociales, políticas y económicas. Del mismo modo, obtendrá una visión panorámica de lo que constituye el teatro de ópera en el siglo XXI, desde los agentes artísticos implicados en que las producciones sean viables, atractivas y adquieran una verdadera función social, hasta el papel que juega la crítica, los medios de información y comunicación, así como los recursos audiovisuales y el cine.

\section{BIBLIOGRAFÍA}

Abbate, C.; y Parker, R. (2012). A History of Opera: The Last Four Hundred Years. New York: W. W. Norton.

Alier, R. (2002). Historia de la ópera. Barcelona: Ma non troppo.

Asensio, M. (1998). “El nacimiento del saxofón”. Doce Notas, 11, pp. 17-21.

Bianconi, L. (ed.) (1986). La drammaturgia musicale. Bologna: Il Mulino.

Bianconi, L.; y Pestelli, G. (1987-1988). Storia dell'opera italiana, 6 vols. Torino: EDT musica.

Bianconi, L.; y Pestelli, G. (2002). Opera on Stage. Chicago/London: University of Chicago Press.

Dahlhaus, C. (1986). "Le strutture temporali nel teatro d'opera". En L. Bianconi, (ed.), La drammaturgia musicale, pp. 183-193. Bologna: Il Mulino.

algunos aciertos"; p. 309(4), "por citar a los artistas más relevantes"; p. 318(2), "músicas populares urbanạs"; p. 320(4), "uno de los títulos"; p. 322(2), "Szymanovsky"; p. 323(4), "hay en el trabajo de Berg" / "en el trabajo de Berg hay"; p. 333(1), "a través del canto ha subsistido"; p. 341(4), "Émilie (2010)" (con cursiva); p. 341(5), "Benjamin" (al final del párrafo); p. 345(3), "celebradas, incluso amadas. Pero solamente una diva puede reinar". 


\section{RESEÑAS DE LIBROS}

Dahlhaus, C. (2005). Drammaturgia dell'opera italiana. Torino: Alfieri.

Döhring, S. (1986). "Giacomo Meyerbeer: Il Grand Opéra come dramma d’idee”. En L. Bianconi, (ed.), La drammaturgia musicale, pp. 365-381. Bologna: Il Mulino.

Elson, A. (2017). A Critical History of Opera: Giving an Account of the Rise and Progress of the Different Schools. Harvard: Harvard University.

Everist, M. (2005). Giacomo Meyerbeer and Music Drama in Nineteenth-Century Paris. Aldershot: Ashgate Publishing.

Fernán Flórez, I. (1885). “El libro del año”. La Ilustración Ibérica, 14-02-1885, p. 2.

Fryer, P. (ed.) (2014). Opera in the Media Age: Essays on Art, Technology and Popular Culture. North Carolina: McFarland \& Company.

Gossett, P. (2012). "Giuseppe Verdi and the Italian Risorgimento". Proceedings of the American Philosophical Society, 156/3, pp. 271-282.

Grout, D.; y Weigel W., H. (2003). A Short History of Opera. New York: Columbia University Press. (1ª ed., 1947).

Kerman, J. (2005). Opera as Drama. California: University of California Press.

Kimbell, D. (1991). Italian Opera. Cambridge: Cambridge University Press.

Lacombe, H. (2001). The keys to French Opera in the Nineteenth Century. London: University of California Press, 2001.

Lindenberger, Herbert (1998). Opera in History: From Monteverdi to Cage. Stanford: Stanford University Press.

Osthoff (1986). "Musica e versificazione: funzioni del verso poetico nell'opera italiana". En L. Bianconi, (ed.), La drammaturgia musicale, pp. 125-142. Bologna: Il Mulino.

Parker, R. (ed.) (1994). The Oxford Illustrated History of Opera. Oxford: Oxford University Press.

Parker, R. (2012). "Verdi politico: a wounded cliché regroups". Journal of Modern Italian Studies, 17, pp. 427-436. 


\section{RESEÑAS DE LIBROS}

Pauls, B. (1996). Giuseppe Verdi und das Risorgimento: ein politischer Mythos in der Nationenbildung. Berlín: Akademie Verlag.

Peña y Goñi, A. (1881). La ópera española y la música dramática en España en el siglo XIX. Madrid: Impresión y Esterotipia de 'El Liberal'.

Powers, H. S. (1987). "La solita forma and The Uses of Convention". Acta Musicologica, LIX/1, pp. 65-90.

Sadie, S. (1990). History of Opera. New York: W. W. Norton.

Snowman (2009), The Gilded Stage: A Social History of Opera. London: Atlantic Books.

Symonds, D.; y Karantonis, P. (eds.) (2013). The Legacy of Opera: Reading Music Theatre as Experience and Performance. Amsterdam/New York: Editions Rodopi B. V.

Till, Nicholas (ed.) (2012). The Cambridge Companion to Opera Studies. Cambridge: Cambridge University Press.

Francisco Manuel López Gómez Centro de Investigación y Documentación Musical (CIDoM)-Unidad Asociada al CSIC 